OPEN ACCESS

Edited by:

Dong Wang,

University of Massachusetts Amherst,

United States

Reviewed by:

Christian Staehelin,

Sun Yat-sen University, China

Maria Jose Soto

Consejo Superior de Investigaciones

Cientificas (CSIC), Spain

*Correspondence:

Sharon R. Long

srl@stanford.edu

sharon.long@stanford.edu

†Present address:

Claus Lang,

DuPont Industrial Biosciences, Wilmington, DE, United States

Specialty section: This article was submitted to

Plant Microbe Interactions, a section of the journal

Frontiers in Plant Science

Received: 06 November 2017 Accepted: 15 January 2018

Published: 07 February 2018

Citation:

Lang C, Smith LS, Haney CH and Long SR (2018) Characterization of Novel Plant Symbiosis Mutants

Using a New Multiple

Gene-Expression Reporter

Sinorhizobium meliloti Strain.

Front. Plant Sci. 9:76.

doi: 10.3389/fpls.2018.00076

\section{Characterization of Novel Plant Symbiosis Mutants Using a New Multiple Gene-Expression Reporter Sinorhizobium meliloti Strain}

\author{
Claus Lang ${ }^{\dagger}$, Lucinda S. Smith, Cara H. Haney and Sharon R. Long* \\ Gillbert Lab, Department of Biology, Stanford University, Stanford, CA, United States
}

The formation of nitrogen fixing root nodules by Medicago truncatula and Sinorhizobium meliloti requires communication between both organisms and coordinated differentiation of plant and bacterial cells. After an initial signal exchange, the bacteria invade the tissue of the growing nodule via plant-derived tubular structures, called infection threads. The bacteria are released from the infection threads into invasion-competent plant cells, where they differentiate into nitrogen-fixing bacteroids. Both organisms undergo dramatic transcriptional, metabolic and morphological changes during nodule development. To identify plant processes that are essential for the formation of nitrogen fixing nodules after nodule development has been initiated, large scale mutageneses have been conducted to discover underlying plant symbiosis genes. Such screens yield numerous uncharacterized plant lines with nitrogen fixation deficient nodules. In this study, we report construction of a $S$. meliloti strain carrying four distinct reporter constructs to reveal stages of root nodule development. The strain contains a constitutively expressed lac $Z$ reporter construct; a $P_{\text {exoy }}$-mTFP fusion that is expressed in infection threads but not in differentiated bacteroids; a $P_{\text {bac }}$-mcherry construct that is expressed in infection threads and during bacteroid differentiation; and a $P_{\text {nifH }}$-uidA construct that is expressed during nitrogen fixation. We used this strain together with fluorescence microscopy to study nodule development over time in wild type nodules and to characterize eight plant mutants from a fast neutron bombardment screen. Based on the signal intensity and the localization patterns of the reporter genes, we grouped mutants with similar phenotypes and placed them in a developmental context.

Keywords: root-nodule, symbiotic nitrogen fixation, bacteroid, differentiation, infection thread, fluorescentreporter strain

\section{INTRODUCTION}

Many legumes interact symbiotically with nitrogen-fixing soil bacteria, collectively called rhizobia. Rhizobium-legume symbioses involve the formation of root nodules, specialized plant organs, where bacteria receive plant-derived dicarboxylic acids in exchange for reduced nitrogen sources (Lodwig and Poole, 2003; Long, 2015). Root nodule formation is initiated when plants sense a bacterial lipochitooligosaccharide, Nod factor, which is produced by compatible rhizobia in the presence of certain flavonoids in root exudates. Detection of Nod factor by specific Nod factor 
receptors leads to the activation of a signaling cascade (refer to Oldroyd, 2013 for a detailed review). The activation of this signaling cascade causes modified growth of root hairs around associated bacteria, accompanied by dedifferentiation of root pericycle, endodermis and cortical cells to form the nodule primordium (Xiao et al., 2014). Rhizobia invade the plant tissue via infection threads which first form in root hairs but ultimately penetrate deep into the plant tissue (Gage, 2004). Certain legumes such as Pisum, Trifolium, Vicia, and the model plant Medicago truncatula produce indeterminate nodules with a persistent meristem at the nodule tip. In $M$. truncatula nodules, plant host cells and also bacteria within symbiosomes undergo a differentiation process characterized by transcriptional and metabolic differentiation, genome endoreduplication and morphological changes (Prell and Poole, 2006; Gibson et al., 2008; Kereszt et al., 2011; Kondorosi et al., 2013; Udvardi and Poole, 2013; Roux et al., 2014; Lang and Long, 2015). Continuous division of plant meristem cells, infection, and differentiation results in a spatial zonation of developmental stages within the nodule organ along a distal to proximal axis. Based on plant cell morphology, five zones can be distinguished in Medicago nodules: the meristematic zone I; infection zone II; interzone IIIII; nitrogen fixation zone III; and senescence zone IV (Truchet and Dazzo, 1982). The zones are characterized by specific bacterial forms. The meristematic zone is devoid of bacteria. In the infection zone, most bacteria are present in infection threads and morphologically resemble free-living bacteria. In the interzone II-III bacteria have been released into symbiosomes and differentiate into elongated Y-shaped bacteroids, which start to fix nitrogen in the nitrogen fixation zone, and senescing bacteroids are found in the senescence zone (Vasse et al., 1990).

Sinorhizobium meliloti the natural symbiotic partner of Medicago sativa has been widely used as a model organism to study root nodule formation with $M$. sativa and M. truncatula. Rhizobia such as $S$. meliloti face different environmental conditions in different root nodule zones and at different developmental stages. The production of exopolysaccharides such as succinoglycan or galactoglucan was found to be critical for infection thread formation (Glazebrook and Walker, 1989; Gonzalez et al., 1996; Cheng and Walker, 1998; Pellock et al., 2000). Exopolysaccharides act as signal molecules that are recognized by a specific plant receptor in the epidermis to regulate nodule development (Kawaharada et al., 2015). In addition, exopolysaccharides can protect bacteria against oxidative stress (Lehman and Long, 2013) and they may suppress MAMP-induced plant defense responses (Aslam et al., 2008).

The bacA gene is prominently involved in bacteroid differentiation in interzone II-III (Kereszt et al., 2011; Kondorosi et al., 2013). BacA mutants fail to differentiate into bacteroids and senesce soon after their release from infection threads (Glazebrook et al., 1993). BacA protects bacteria from plant-derived antimicrobial peptides and is involved in the incorporation of very long-chain fatty acids into Lipid A (Karunakaran et al., 2010; Haag et al., 2011, 2013).

In the interzone II-III, conditions change from oxic to microoxic. This is an essential prerequisite for nitrogen fixation, because the nitrogenase enzyme is highly oxygen sensitive. In fact, genes encoding the nitrogen fixation apparatus are only expressed under microoxic conditions (Soupène et al., 1995; Bobik et al., 2006). Microoxic conditions are established by increased respiration and the expression of nodule-specific hemeproteins, the leghemoglobins, which give nodules a characteristic pinkish hue. Binding of $\mathrm{O}_{2}$ by leghemoglobin is essential for decreasing the abundance of free oxygen while also facilitating a high flux of oxygen to the bacteroid compartment in the nitrogen fixation zone (Ott et al., 2005).

After the bacteria are released from infection threads into symbiosomes the bacteria are exposed to new conditions, including a multitude of plant-produced nodule-specific peptides (Alunni and Gourion, 2016; Pan and Wang, 2017; Ribeiro et al., 2017). The secretion of these peptides from the plant cytoplasm into the symbiosome is essential for bacteroid differentiation. $M$. truncatula encodes more than 450 nodule-specific cysteinerich (NCR) and glycine-rich peptides (NGR) (Kevei et al., 2002; Kereszt et al., 2011; Haag et al., 2013). Few of these proteins have been characterized at present. Some peptides have antimicrobial properties, induce bacteroid differentiation, and control bacterial infection (Van de Velde et al., 2010; Haag et al., 2011; Tiricz et al., 2013; Farkas et al., 2014), and there may be other so-far cryptic roles.

Genetic analysis has helped established the roles for plant proteins. Several plant mutants were identified that are deficient in nitrogen fixation $(d n f)$ but are able to form nodules (Kuppusamy et al., 2004; Veereshlingam et al., 2004; Starker et al., 2006; Domonkos et al., 2013; Horváth et al., 2015). Characterization and mapping of these $d n f$ mutations can provide information about the processes that control root nodule development. For instance, the $d n f 1$ mutation was mapped to a signal peptidase subunit, which is required for NCR secretion (Van de Velde et al., 2010; Wang et al., 2010). The dnf2 mutation was mapped to a protein with a signal peptide and a phosphatidylinositol-specific phospholipase CX domain (Bourcy et al., 2012). The $d n f 4$ and $d n f 7$ mutations were mapped to the NCR peptides NCR211 and NCR169, respectively (Horváth et al., 2015; Kim et al., 2015). Study of host-microbe strain specificity has revealed a role for NCR peptides in allowing the plant to discriminate among bacterial symbionts (Pan and Wang, 2017).

Large scale Tnt1, fast neutron bombardment and ethanemethylsulfonate mutagenesis screens have yielded several hundred M. truncatula symbiosis mutants (Penmetsa and Cook, 2000; Wang et al., 2006; Tadege et al., 2008; Pislariu et al., 2012; Veerappan et al., 2016), most of which have not yet been characterized in detail. Initial characterization of plant nodule mutants may include staining of cellular components or bacterial cells with fluorescent or conventional dyes (Dudley et al., 1987; Haynes et al., 2004) or the use of bacterial reporter strains expressing $\beta$-galactosidase or $\beta$-glucuronidase fusions (Leong et al., 1985; Oke and Long, 1999; Starker et al., 2006). Green and red fluorescent reporter proteins such as GFP and DsRed have been used successfully to follow infection thread development (Gage et al., 1996; Gage, 2002) and to study emerging root nodules (Pistorio et al., 2002). Use of fluorescent proteins in older, fully developed nodules was found to be problematic due to diminished fluorescence in the nitrogen fixation zone 
(Stuurman et al., 2000), though uniform labeling was found for enhanced GFP (eGFP)-expressing $S$. meliloti in all zones of Medicago sativa nodules (Pini et al., 2013).

Here, we report the construction and application of a S. meliloti reporter strain that expresses three developmentally timed reporter genes, each at a different symbiotic stage, plus a constitutive reporter. In contrast to previous studies that used one constitutively expressed fluorophore or indiscriminate staining of all nodule bacteria, our strain can reveal the localization of different bacterial subpopulations in a nodule. We used this strain to analyze different stages of wild type $M$. truncatula nodule development, and to characterize plant mutants with impaired nodule development.

\section{MATERIALS AND METHODS}

\section{Plant and Bacterial Cultivation}

All bacterial cultures were grown in modified Luria-Bertani medium (Meade et al., 1982). Streptomycin $(500 \mu \mathrm{g} / \mathrm{ml})$, neomycin $(100 \mu \mathrm{g} / \mathrm{ml})$, tetracycline $(5 \mu \mathrm{g} / \mathrm{ml})$, and spectinomcyin $(50 \mu \mathrm{g} / \mathrm{ml})$ were added to $S$. meliloti cultures if appropriate. For E. coli cultures kanamycin $(25 \mu \mathrm{g} / \mathrm{ml})$ was used instead of neomycin and chloramphenicol was added at $50 \mu \mathrm{g} / \mathrm{ml}$ if appropriate.

Medicago truncatula [Gaertn.] A17 and mutant seeds were lightly scratched with sandpaper and sterilized in undiluted commercial sodium hypochlorite bleach for $5 \mathrm{~min}$. After rinsing with sterile water, seeds were imbibed for $8 \mathrm{~h}$ at room temperature and $48 \mathrm{~h}$ at $4^{\circ} \mathrm{C}$. Seeds were germinated overnight in inverted petri dishes in the dark and planted into pre-sterilized vermiculite in cone-tainer tubes (Stuewe \& Sons, Tangent). Plants were watered every third day with $5 \mathrm{ml} 0.1 \times$ BNM. Five day old seedlings were inoculated with $5 \mathrm{ml}$ of a suspension $\left(\mathrm{OD}_{600}=0.1\right)$ of S. meliloti in $0.5 \times$ Buffered Nodulation Medium (BNM) (Ehrhardt et al., 1992).

\section{Construction of a Multireporter S. meliloti Strain}

The Sinorhizobium meliloti strain CL150 was used as a wild type and expression host throughout this study. CL150 is a Sinorhizobium meliloti 1021 derivative, corrected for point mutations in pstC and ecfR1 (Schlüter et al., 2013).

To generate reporter constructs, the genes encoding monomeric teal fluorescent protein gene, $m$ TFP (Ai et al., 2006), and the E. coli $\beta$-glucuronidase, uidA, were PCR amplified from the plasmids pNCS-mTFP1 and pVO155, respectively (Supplementary Table S1). Hetero-stagger cloning was used to clone the reporter genes (Felfoldi et al., 1997) into pCAP77, which carries a rhaS fragment and can integrate into the rhaS locus in the S. meliloti genome (Pinedo and Gage, 2009). Basically, two PCRs with primer pairs of slightly different length (Supplementary Table S2) were carried out. The PCR products were gel-purified, mixed, melted and reannealed. Annealing of strands from the different PCRs resulted in the formation of sticky ends. The annealed PCR products were cloned into the KpnI site of pCAP77 generating pCL141 (uidA) and pCL146 (mTFP). The nifH and exoY promoters were amplified from CL150 genomic DNA using two sets of primers for each promoter; hetero-stagger cloning was used to integrate these promoters into the KpnI site upstream of the reporter genes in pCL141 or pCL146, resulting in pCL169 $\left(P_{\text {nifH-uidA }}\right)$

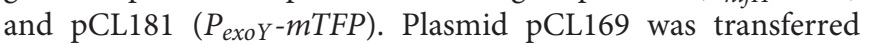
into S. meliloti CL150 by conjugation and integrated into the rhas locus to generate strain CL227 (Pinedo and Gage, 2009). Since genomic insertion strains of $P_{\text {exoY }}-m t f p$ only displayed weak fluorescence, $P_{\text {exoY- }}-m t f p$ was amplified with primers CL348/CL351 and cloned into the EcoRV site of multicopyplasmid pMB393, generating pLS1. To generate a $P_{b a c A}-m$ Cherry fusion, mCherry was amplified from pCH179 with primers CL527/CL528 and $P_{b a c A}$ was amplified from genomic DNA using primers CL523/CL525. The two PCR products were spliced together by overlap extension PCR (Horton et al., 1989) and the resulting $P_{b a c A}-m$ Cherry PCR product was cloned into the SmaI site of pLS1 to generate pCL301. This plasmid was conjugated into CL150 to generate CL296 and into LS121, which is a CL227 derivative containing the hemA::lacZ plasmid pXLGD4 (Leong et al., 1985), to generate CL304. Strain descriptions are listed in Supplementary Table S3. Plasmids pCL301 and pXLGD4 are compatible as they have a pBBR (Kovach et al., 1995) and a pRK290 origin (Ditta et al., 1985), respectively.

\section{Preparation, Staining, and Microscopy of Root Nodule Sections}

Root nodules were harvested by cutting the root $1 \mathrm{~mm}$ above and below a nodule. The three most developed nodules of ten plants were placed in cryomolds so that each cryomold contained ten nodules from different plants. The nodules were embedded with OCT (Sakura Tissue-Tek) and frozen by floating the cryomold in a polypropylene lid of a pipette-tip box on liquid nitrogen. Frozen nodules were stored at $-80^{\circ} \mathrm{C}$. Using a Cryotome (Microm HM550, Thermo Fisher Scientific), $25 \mu \mathrm{m}$ sections were prepared at $-20^{\circ} \mathrm{C}$. The sections were transferred to adhesive coated microscopic slides (CFSA CS-1/2X, Instrumedics) using the CryoJane Tape-Transfer System (Instrumedics). The sections were incubated in phosphate buffered saline for $10 \mathrm{~min}$ to dissolve OCT. For the detection of fluorescent proteins, several sections from every cryoblock were mounted with mounting medium (90\% glycerol, 0.01 M sodium phosphate buffer $(\mathrm{pH} 7)$, $0.3 \% \mathrm{w} / \mathrm{v} n$-propyl gallate). For fluorescent GUS staining, sections were stained with $10 \mu \mathrm{M}$ ImaGene Green $\mathrm{C}_{12}$ FDGlcU (LifeTechnologies) diluted in $50 \mathrm{mM}$ sodium phosphate buffer $(\mathrm{pH} 7)$ for $1 \mathrm{~h}$ at $37^{\circ} \mathrm{C}$. The slides were washed twice before mounting. Images from whole root nodule sections were acquired with a Leica DM2500 wide field microscope equipped with a X-Cite 120LED light source and a $10 \times$ lens. Specific filter sets were used for mCHERRY, mTFP, ImaGene Green and UV autofluorescence detection. The exposure was set to either $800 \mathrm{~ms}$ for mTFP, mCHERRY and UV autofluorescence or to $600 \mathrm{~ms}$ to detect ImaGene Green. For the statistical analysis of nifH promoter activity in nodules from CL304 inoculated plants, root nodules were harvested at $28 \mathrm{dpi}$ and bisected transversely with respect to the root axis. Five plants with 
an average of 10 nodules per plant were processed for each plant line. Staining for $\beta$-glucuronidase activity was performed with 5-bromo-4-chloro-3-indolyl-D-glucuronic acid (X-gluc) as described (Swanson et al., 1993). High magnification images to visualize bacteroids within the plant tissue were taken with a Leica SP5 confocal microscope and a $63 \times$ objective lens.

\section{Purification and Imaging of Nodule Bacteria}

Nodules from M. truncatula A17 plants inoculated with CL304 were harvested at $17 \mathrm{dpi}$ and stored at $-80^{\circ} \mathrm{C}$. Fifty frozen nodules from 10 plants were crushed with a microcentrifuge pestle. The tissue was resuspended in $1 \mathrm{ml}$ PBS and carefully passed through two layers of Miracloth (EMD Millipore) using a syringe and filter assembly. The bacteria in the filtrate were sedimented by centrifugation at $3000 \mathrm{~g}$ for $5 \mathrm{~min}$ and resuspended in $200 \mu \mathrm{l}$ PBS. GUS staining was carried out by adding ImaGene Green $\mathrm{C}_{12}$ FDGlcU to a concentration of $10 \mu \mathrm{M}$ and incubating at $37^{\circ} \mathrm{C}$ for $1 \mathrm{~h}$. Stained and unstained bacteria were mounted on agarose pads ( $1 \%$ agarose in phosphate buffered saline ( $\mathrm{pH} 7$ ) and imaged using a wide-field microscope (Leica DM2500) and a $100 \times$ objective lens.

\section{RESULTS}

\section{Construction of a Multireporter S. meliloti Strain}

We constructed an S. meliloti strain with several reporter gene fusions, each activated during different symbiotic stages, to characterize plant nodulation mutants. We selected the promoters of exo $Y, b a c A$, and nifH because these three genes were previously used to assess nodule development of plant mutants (Starker et al., 2006). The exoY promoter serves as a reporter for bacterial gene expression during early symbiotic stages. The exoY gene is the first gene of the exoYF1Q operon and encodes a galactosyl transferase that catalyzes the first step of succinoglycan production (Müller et al., 1993; Cheng and Walker, 1998). Succinoglycan is essential for early symbiotic stages, particularly, the initiation and elongation of infection threads (Cheng and Walker, 1998). Transcriptomic studies showed that exoY is expressed more highly in free-living bacteria and the nodule tip than in mature bacteroids (Barnett et al., 2004; Roux et al., 2014). The bacA promoter serves as a reporter for bacterial gene expression during bacteroid differentiation. The bacA gene is essential for the differentiation of rod-shaped bacteroids into elongated nitrogen-fixing bacteroids in galegoid root nodules (Long et al., 1988; Karunakaran et al., 2010; Haag et al., 2013). Reporter gene assays and transcriptomic studies showed that bacA is primarily expressed in the interzone II-III in root nodules (Glazebrook et al., 1993; Roux et al., 2014). We chose the nifH gene that encodes the homodimeric iron $(\mathrm{Fe})$ protein (component II) of nitrogenase as a reporter for expression of the nitrogen fixation apparatus. The nifHDK operon includes also nifKD, encoding the subunits of component I, dinitrogenase [reviewed in (Fischer, 1994)]. Like other nif and fix genes, nifH is regulated by the FixJ/FixL two-component system, which induces expression of the nitrogen fixation apparatus via intermediate regulators FixK and NifA under microoxic conditions (Bobik et al., 2006). Therefore, nifH expression indicates expression of nitrogen fixation genes and reflects a low-oxygen local environment in nodules.

After testing several different reporter genes including cyan (CFP), green (GFP), red (mCherry), teal (mTFP), and flavinbinding protein derived fluorescent proteins (EcFbFp and Pp1FbFp) with an E. coli trp promoter (data not shown), we decided to use mTFP and mCherry to assess exo $Y$ and bacA promoter activity, respectively. As most fluorescent proteins require the presence of molecular oxygen for fluorophore formation and as non-oxygen requiring fluorescent proteins (EcFbFp and Pp1FbFp) did not yield sufficient fluorescence intensities in our hands, we used the $\beta$-glucuronidase (GUS) encoding uidA gene to assess nifH expression. Promoter fusions of $P_{\text {exoY-mTFP }}$ and $P_{b a c A}-m$ Cherry were cloned on a pBBRbased plasmid that replicates in $S$. meliloti. The $P_{n i f H}-G U S$ fusion was integrated into the genome in the rhaS locus using the previously described pCAP77 plasmid (Pinedo and Gage, 2009). In addition to exo $Y$, bacA, and nifH promoter fusions we also included plasmid pXLGD4, which contains a constitutively active hemA::lacZ fusion, as a general bacterial marker in the final multireporter S. meliloti strain. The hemA::lacZ fusion has been used in the past to visualize early symbiotic stages such as infection thread formation in root hairs (Haney and Long, 2010). While we did not use the hemA::lacZ fusion in this study, it would be useful in future studies characterizing early symbiosis mutants.

With a single bacterial strain able to express distinct reporters for several developmental states, it should be possible to characterize the developmental state of a plant mutant by inspection of a few nodules. We evaluated the feasibility of this approach by testing the multi-reporter strain on wild type plants and already-characterized $d n f$ mutants.

\section{The Expression and Localization of Reporter Constructs Changes during Root Nodule Development}

We inoculated wild type $M$. truncatula A17 with the multireporter strain CL304 and harvested nodules at 7, 10, 14,17 , and 21 days post infection (dpi). We prepared root nodule cryo-sections to assess reporter gene-expression by fluorescence microscopy. We found that teal (mTFP) and red (mCherry) fluorescence signals are preserved in almost all cryosections of 7 , 10,14 , and 17 dpi samples but only in approximately $20 \%$ of the 21 dpi samples (data not shown). We did not pursue analysis of 21 dpi samples but focused on younger root nodules with stable fluorescence. We speculate that the environmental conditions inside the nodule change during development, resulting in conditions that do not permit fluorophore formation. It is also possible that bacterial cells may have lost the plasmid after prolonged incubation in root nodules.

Teal $\left(P_{\text {exoY }}-m T F P\right)$ fluorescence was mostly confined to infection threads in 7, 10, 14, and 17 dpi nodules (Figures 1A-D). 

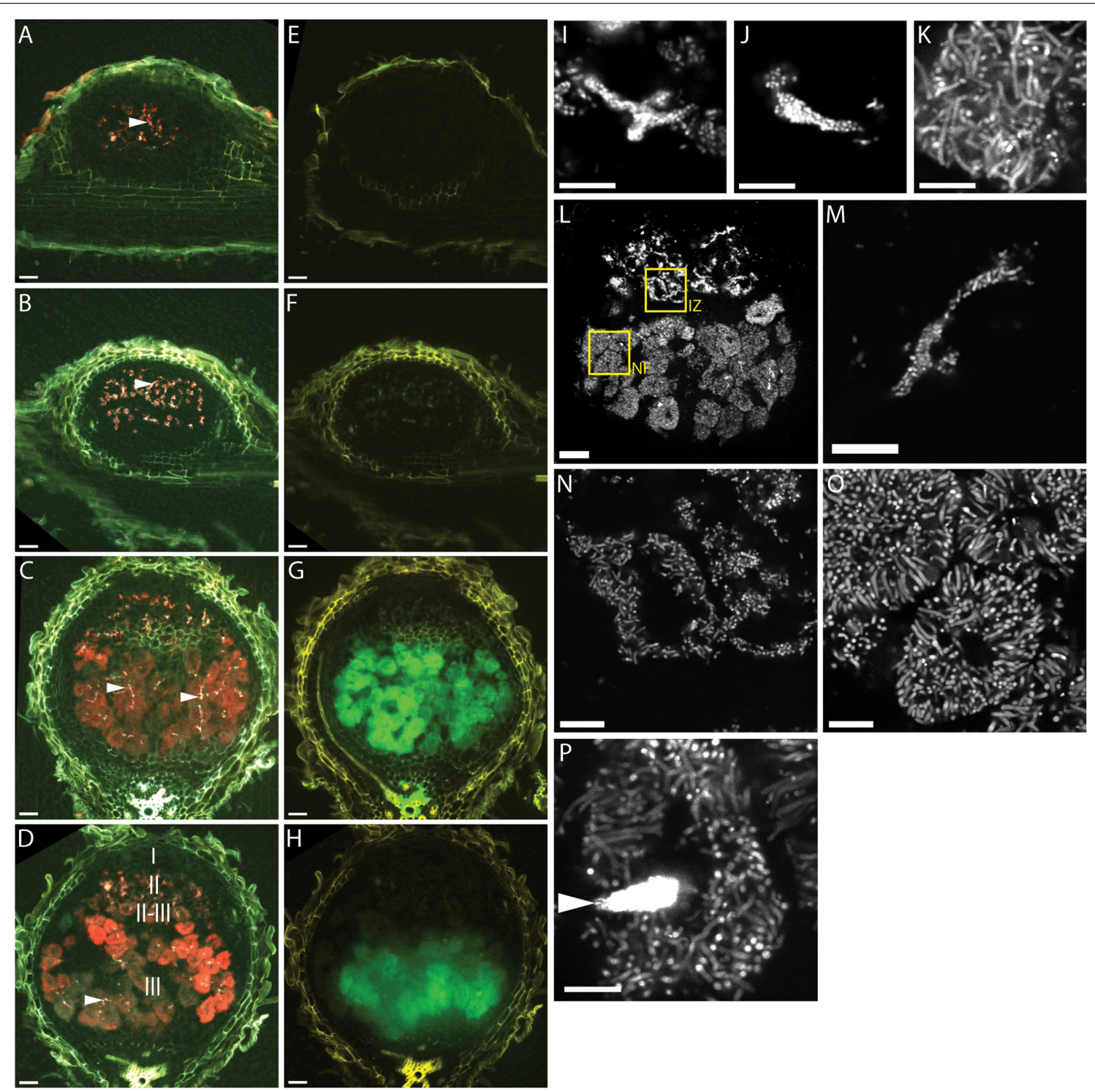

FIGURE 1 | Fluorescence microscopy of wild type Medicago truncatula A17 root nodules at different times after inoculation with CL304. (A-H) Widefield micrographs of root nodules harvested 7 (A,E), 10 (B,F), 14 (C, G), and 17 (D, H) days after inoculation. The first column (A-D) shows composite images of the

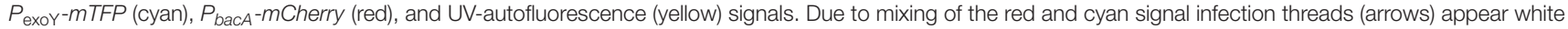
in the images. The second column (E-H) shows composite images of the $P_{\text {nifH }}$-uidA (green) and UV-autofluorescence (yellow) signals in ImaGene Green stained nodules. Images (I-P) are confocal images of $P_{\text {bacA }}-m$ Cherry expressing CL304 bacteria in 7 (I), 10 (J), 14 (K), or 17 (L-P) day old nodules. Image (L) is a confocal overview image of a nodule at $17 \mathrm{dpi}$. The two boxed areas indicate regions from the interzone II-III (IZ) and the nitrogen fixation zone (NF) that are magnified in images $\mathbf{( N )}$ and $\mathbf{( O )}$, respectively. Image $\mathbf{( M )}$ is a magnification of an infection thread. Image (P) shows a plant cell with moderately fluorescent elongated bacteroids and an infection thread (arrow) with highly fluorescent bacteria. The different root nodule zones, I (meristem), II (infection), II-III (interzone), and III (nitrogen fixation) are indicated in image (D). Scale bars: $50 \mu \mathrm{m}$ (whole nodule images, A-H,L); $5 \mu \mathrm{m}$ (confocal images, I-K, M-P).

This indicates that the exoY promoter is most active in infection threads and is turned off when bacterial cells are released from infection threads into plant cells. We detected a weak signal in bacterially invaded plant cells at $14 \mathrm{dpi}$ and later time points; however, a teal-fluorescent signal of similar intensity is observed in control nodules inoculated with a non-fluorescent control strain (Supplementary Figure S1), thus we believe that the tealfluorescent signal in late-stage bacterially invaded plant cells is largely due to host plant autofluorescence.
At 7 and 10 days, the red-fluorescent $P_{b a c A}$-mCherry is detected primarily in infection threads and the pattern matches the $P_{\text {exoY }}$-mTFP signal (Figures 1A,B). In $14 \mathrm{dpi}$ and older nodules the $P_{b a c A}-m C h e r r y$ signal is also detected in bacterially invaded plant cells (Figures 1C,D). $P_{b a c A}-m$ Cherry fluorescence was detected in invaded plant cells in the proximal part of the infection zone, the interzone II-III and in the nitrogen fixation zone. This indicates that the $b a c A$ promoter is active both in infection threads and in bacteroids. Considering bacA's 
importance for bacteroid differentiation, we expected that $P_{b a c A}$ is most active in the proximal part of the infection zone and interzone II-III. In most 14 dpi nodules we did not observe differences of the fluorescence intensity between the interzone IIIII and the nitrogen fixation zone, but in some of the older, more elongated nodules $P_{b a c A}-m$ Cherry fluorescence was brightest in the interzone II-III and decreased towards the nodule base (data not shown). Using fluorescent GUS substrate ImaGene Green, we detected $P_{\text {nifH- }}$ uidA activity in 14 dpi and older nodules but not in 7 and 10 dpi nodules (Figures 1E-H). This indicates that $P_{\text {nifH }}$ is activated at $10-14$ dpi.

The $P_{b a c}-m$ Cherry signal intensity in bacteroids was high enough to use high magnification confocal microscopy to image single bacteroids (Figures 1I-P). Confocal microscopy of $m$ Cherry-expressing bacterial cells showed that at days 7 and 10 most bacteria are small and rod-shaped and have not yet differentiated into elongated or branched bacteroids. At days 7 and 10 a few bacteria have been released from infection threads into plant cells (Figures 1I,J). At days 14 (Figure 1K) and 17 (Figures 1L-P) most of the cell lumens of invaded plant cells are filled with bacteroids. In addition, undifferentiated bacteria are visible in infection threads (Figure $\mathbf{1} \mathbf{M}$ ); undifferentiated or partially elongated cells are found in the interzone II-III (Figure 1N); and many fully elongated and branched bacteroids were observed in the nitrogen fixation zone (Figure 10). Notably, the $P_{b a c A}-m C h e r r y$ signal of individual, differentiated bacteroids was only about $10-20 \%$ as bright as the signal of undifferentiated bacteria in infection threads (Figure 1P).

\section{Differences in Reporter Gene Expression and Localization in Plant Mutants with Early, Intermediate, and Late Symbiotic Defects}

We calibrated the multi-reporter strain using previously characterized $d n f$ mutants. We selected the mutants $d n f 5$ (earlyarrest), $d n f 2$ (early-intermediate), $d n f 7$ (intermediate), $d n f 6$ (late), and $d n f 3$ (late) (Starker et al., 2006; Lang and Long, 2015). Since in bacteroid filled plant cells, nifH expression and fully developed bacteroids were visible at 14 and 17 dpi in wild type nodules, we used 14-17 day old nodules to study reporter gene expression in mutant nodules.

Analysis of the $P_{\text {exoY }}$-mTFP signal revealed the presence of infection threads in nodules of all tested plant lines (Figure 2). This confirms that bacteria enter nodules of these $d n f$ mutants. In 14 dpi nodules, the infection threads are found not only near the nodule tip but also near the nodule base. Similar localization patterns and fluorescence intensities for invading bacteria suggest that infection thread formation is not affected by any of the $d n f$ mutants.

We detected red fluorescence signals in all $d n f$ mutants, indicating that bacteria in all the selected $d n f$ plant mutants express bacA. In some cases, (e.g., Figure 2A) we observed a region of very bright fluorescence in the first layer of bacterially invaded plant cells. This was occasionally observed in larger, more developed nodules formed by A17, Jemalong and $d n f 3$, but not in the other mutants. It is possible that at $14 \mathrm{dpi}$ bacA is highly expressed in most bacteroids since they are either in the process of differentiation or have just finished differentiation, whereas for more developed nodules bacA expression is turned off in the fully differentiated bacteroids. The $m$ Cherry expression patterns reveal differences between the $d n f$ mutants in the localization of bacteroids within plant cells. In the intermediateand late-arrest mutants, $d n f 7$ and $d n f 3$, we observed strong $P_{b a c A}-m c h e r r y$ signals in the interzone and the nitrogen fixation zone. Similarly, to wild type nodules, invaded plant cells in the nitrogen fixation zone of $d n f 7$ and $d n f 3$ mutants appeared almost completely red, indicating that bacteroids completely fill out plant cells in the nitrogen fixation zone and that vacuoles become very small. In contrast, in the earlier mutants $d n f 5$ and $d n f 2$ the $P_{b a c A}-m$ Cherry signal is mostly confined to the cell periphery indicating that bacteroids are only found near the cell wall of invaded plant cells in $d n f 2$ and $d n f 5$ nodules. In $d n f 6$ nodules, the $P_{b a c A}$-mcherry signal was not as strong as in the other nodules. Similar to $d n f 2$ and $d n f 5$ nodules, the signal was localized mainly in the cell periphery in nodules from the dnf6 mutant, which, due to a low level of nitrogenase activity, was previously classified as a late-arrest mutant (Starker et al., 2006; Lang and Long, 2015). Confocal imaging confirmed that larger parts of the invaded plant cells in $d n f 2, d n f 5$, and $d n f 6$ nodules than in nodules from other $d n f$ plants were devoid of bacteroids. In addition, we observed differences in cell shape between the different mutants. The bacteroids in $d n f 5$ nodules were not elongated and of similar length as the undifferentiated bacteria in infection threads. The bacteroids in $d n f 2$ and $d n f 6$ were not as large as the bacteroids of the wild type plants but they were longer than the infection thread bacteria or bacteroids in $d n f 5$ nodules. The largest, most-elongated bacteroids were found in wild type, $d n f 7$ and $d n f 3$ nodules. Our findings suggest that bacteroid maturation and/or proliferation is affected by the mutations in $d n f 5, d n f 2$, and $d n f 6$ nodules but not in $d n f 7$ and dnf3 nodules.

We used a fluorescent GUS substrate to detect $P_{\text {nifH }}$-uidA activity in nodule sections. The fluorescence intensities in the different nodule sections showed that at $14 \mathrm{dpi}$ the nifH promoter is active in wild type, $d n f 3, d n f 6$, and $d n f 7$ nodules. In contrast, we did not detect any GUS activity in $d n f 2$ and $d n f 5$ nodules indicating that the activity of the nifH promoter is very low or absent.

\section{Characterization of Potential Nodulation Mutants}

Since the reporter strain proved useful to characterize and classify nodulation mutants, we applied the CL304 reporter strain to putative $M$. truncatula symbiosis mutants that were not previously characterized. We studied eight fast neutron bombardment (FNB) mutant plant lines from the $\bar{M}$. truncatula mutant collection at the Samuel Roberts Noble Foundation. The descriptions from the primary screen indicate that all eight FNB mutants have a Fix- phenotype (Table 1). After 4 weeks of cultivation, the shoots of three mutants $(6168,6265,6488)$ were stunted in comparison to wild type plants (Figure 3). The leaves of these plants appeared yellowish, showing signs of chlorosis. The root nodules of these plants were small, white and 

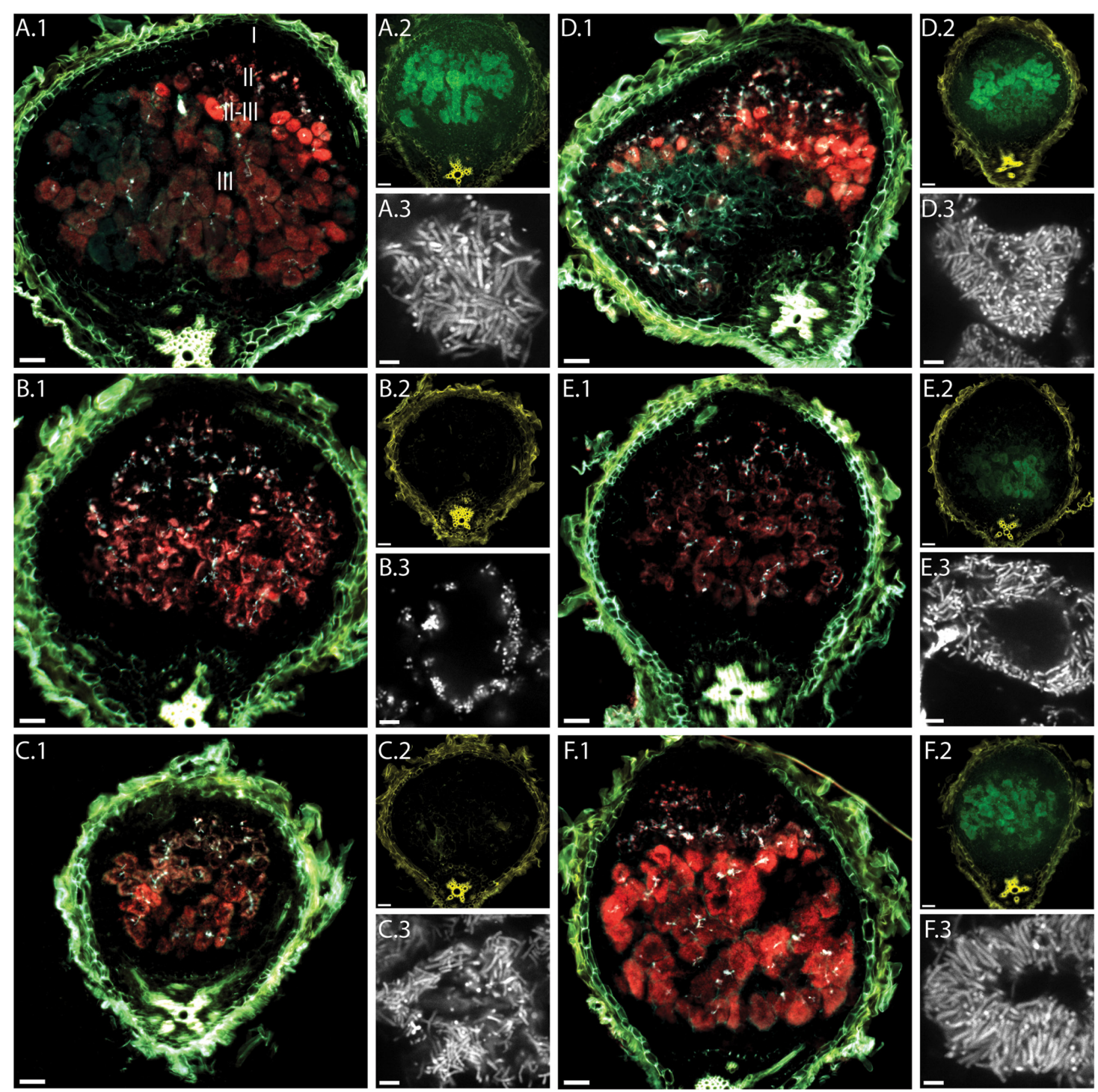

FIGURE 2 | Fluorescence microscopy of root nodules from dnf plant mutants inoculated with CL304. Root nodules from wild type M. truncatula A17 (A) and the mutants $\operatorname{dnf5}(\mathbf{B})$, dnf2 (C), dnf7 (D), dnf6 (E), and dnf3 (F) were imaged at 14 dpi. The large images (A.1-F.1) are composite widefield images of the $P_{\text {exoY-mTFP }}$ (cyan), $P_{\text {bacA }}-m$ Cherry (red), and UV-autofluorescence (yellow) signals. Images (A.2-F.2) are composite widefield images of the $P_{\text {nifH- }}$ uidA (green) and UV-autofluorescence (yellow) signals in ImaGene Green stained nodules. Images (A.3-F.3) are confocal images of $P_{\text {bacA }}$-mCherry labeled bacterial cells within root nodules. The different root nodule zones, I (meristem), II (infection), II-III (interzone), and III (nitrogen fixation) are indicated in image (A.1). Scale bars: $50 \mu \mathrm{m}$ (wide field images); $5 \mu \mathrm{m}$ (confocal images)

spherical whereas wild type nodules were larger, pink and slightly elongated. Two mutants $(6359,6469)$ had normal-sized shoots but the leaves appeared light green, indicating starting chlorosis and the nodules were small, spherical, and not as pink as wild type nodules. After 4 weeks of inoculation with S. meliloti CL304, we did not see strong differences in terms of shoot size, leave, and nodule color between three mutants $(6470,6471,6701)$ and the wild type. Fluorescence microscopy of cryosections showed that teal $P_{\text {exoY }}$-mTFP fluorescent signals are present in nodules of all mutants (Figure 4). This indicates that the nodules from all tested mutants are invaded by bacteria. Activity of the exoY promoter further indicates that succinoglycan biosynthesis is activated in infection thread bacteria as in wild type nodules. The infection thread localization pattern in mutant plant lines was similar to the infection thread pattern of wild type nodules and the infection threads were evenly distributed over different nodule zones in all plant lines. This suggests that infection thread formation is not affected in any of the new FNB-mutants. By contrast, the $P_{b a c A}-m$ Cherry expression patterns differed between the mutants. In one mutant (6265) the red fluorescence signal was almost completely absent in invaded plant cells (Figure 4). This indicates that intracellular bacteria do not express bacA and do not differentiate normally. Confocal microscopy revealed that most bacteria in these nodules remain in infection threads 


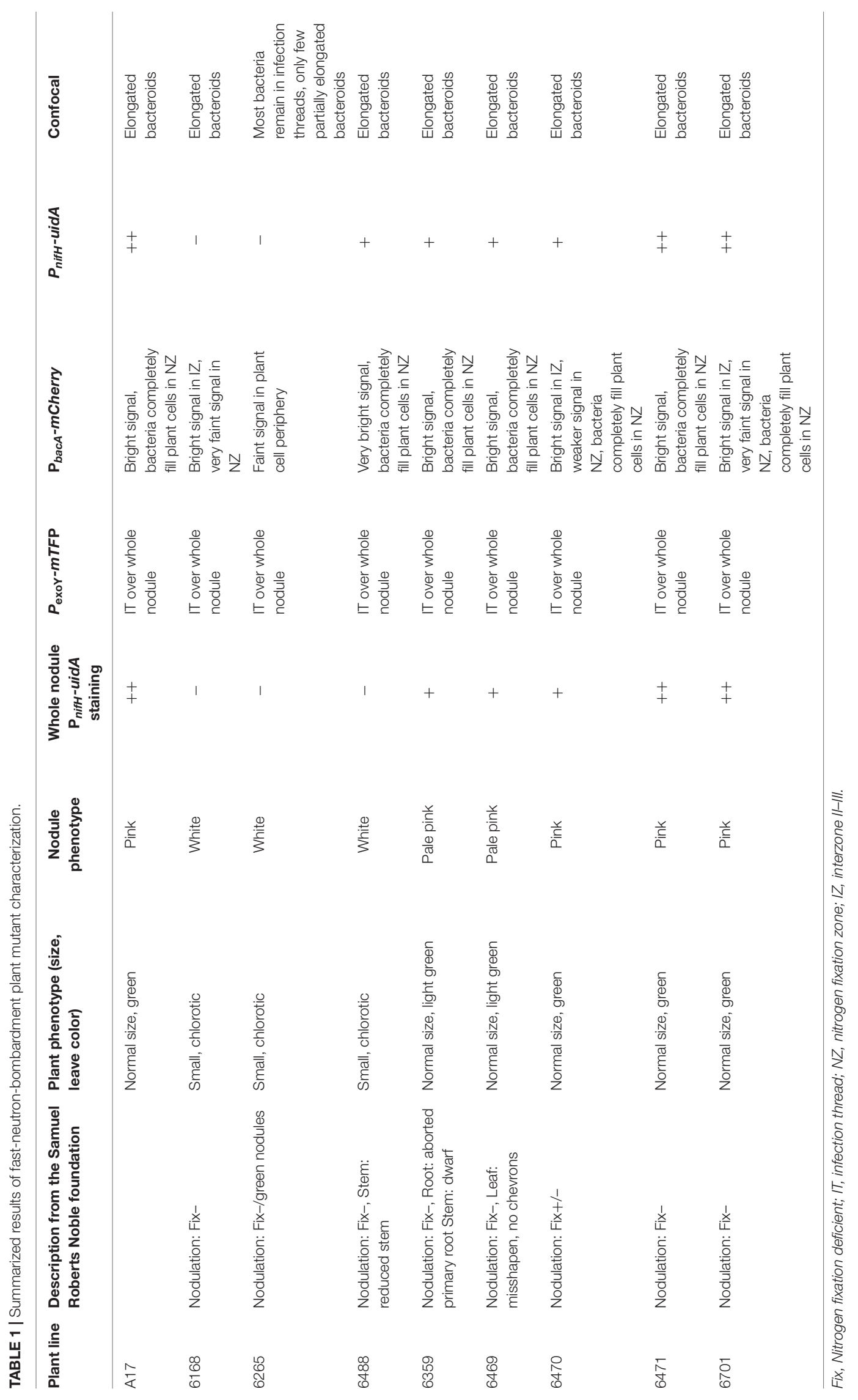



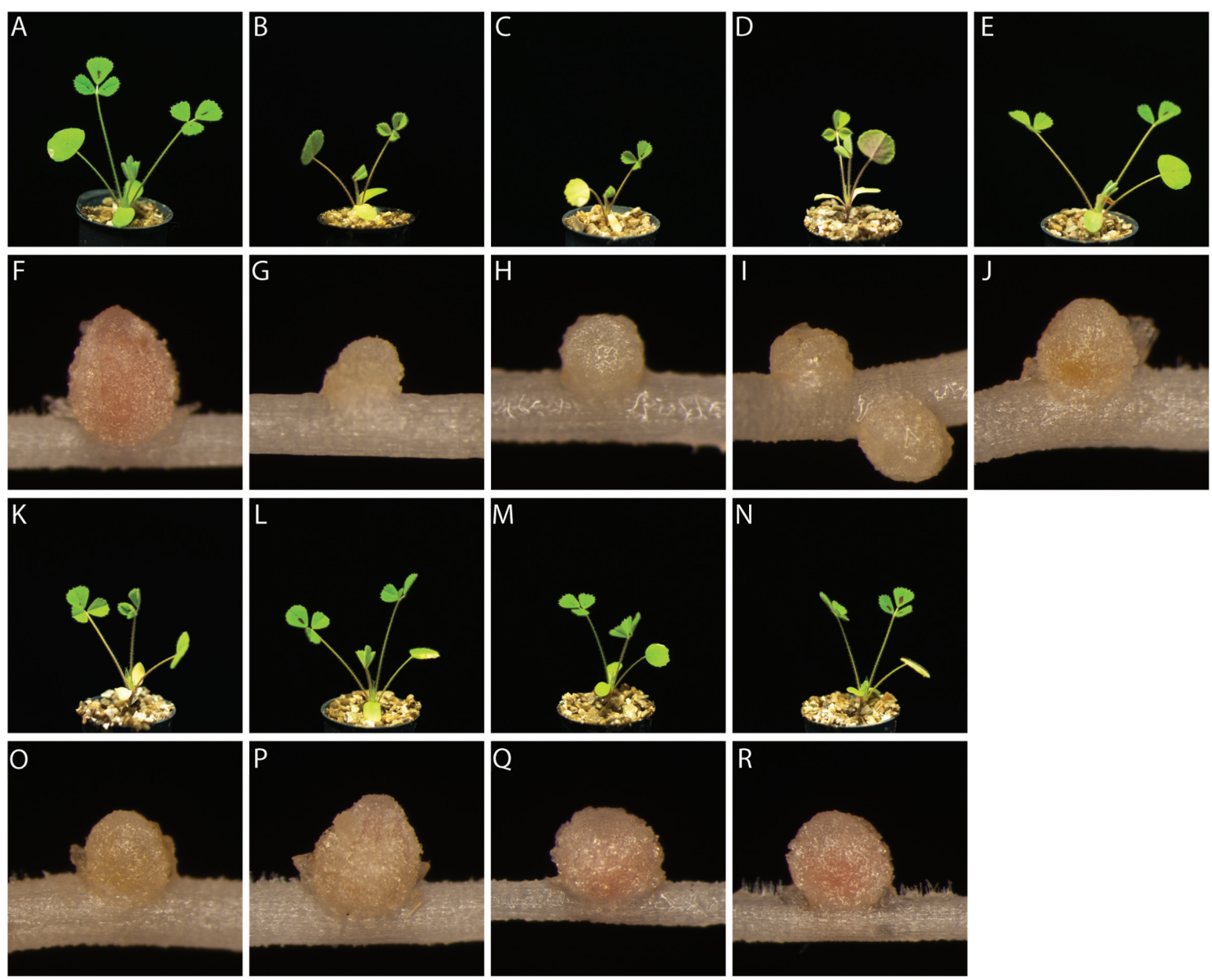

FIGURE 3 | Plant and nodule morphology of FNB plant mutants. Shoots (rows 1 and 3) and root nodules (rows 2 and 4 ) from wild type M. truncatula A17 (A,F) and the mutants 6168 (B,G), 6265 (C,H), 6488 (D,I), 6359 (E,J), 6469 (K,O), 6470 (L,P), 6471 (M,Q), and 6701 (N,R) were imaged at 24 dpi.

and only very few are released into plant host cells. Some of the released bacteria were slightly elongated, suggesting that differentiation is initiated but that the bacteria die before the process is completed. This mutant therefore appears to have a distinct phenotype.

In the nodules from mutant 6168 , the $P_{b a c A}$-mcherry signal is mostly confined to the infection zone and the interzone. Only a few infection pockets display red fluorescence in the nitrogen fixation zone. Magnification of the cells in the interzone (Figures 4B.2) shows bacteria are released into plant cells and differentiate into elongated bacteroids. The absence of intracellular red fluorescent signals in the nitrogen fixation zone suggests that bacteroids senesce prematurely in 6168 nodules.

In nodules of the remaining mutants $(6488,6359,6469,6470$, $6471,6701)$ the $P_{b a c A}$-mcherry signal was seen in the infection zone, interzone and nitrogen fixation zone. In all six cases the appearance of bacterially invaded plant cells resembles nodules of intermediate $(d n f 4)$, late $(d n f 3)$, or wild type nodules as the invaded plant cells appear to be almost completely filled with bacteroids. This indicates that bacteria are able to survive within plant host cells. Confocal imaging demonstrated the presence of elongated bacteroids in all six plant lines, indicating that the bacteroids differentiate and that genome endoreduplication occurs.

We used two different methods to assess expression of the $P_{\text {nifH }}$-uidA reporter fusion. First, we stained nodules from several plants with the non-fluorescent GUS dye, X-gluc, and calculated the percentage of stained, $P_{\text {nifH }}$-positive nodules at $28 \mathrm{dpi}$. While almost all wild type nodules displayed GUS activity the proportion of $P_{\text {nifH }}$ positive nodules was strongly reduced in some of the FNB plant lines (Figure 5). Only approximately $20 \%$ of the nodules from lines, 6168, 6265, and 6488 and approximately $70 \%$ of the nodules from lines 6359 and 6469 showed $P_{\text {nifH }}$ activity (Figure 5). The percentage of $P_{\text {nifH }}$-positive nodules seemed also to be reduced in lines 6470, 6471, 6701, but the difference to wild type was not found to be statistically significant.

In addition, we employed a fluorescent GUS dye, ImaGene Green, to study the localization of the $P_{\text {nifH }}$ promoter activity in cryosections of younger nodules. We saw no $P_{n i f H}-u i d A$ signals in cryosections of 6168 and 6265 sections; observed faint signals in $6488,6359,6469$, and 6470 ; and strong signals in 6471, 6701, and wild type nodules (Figure 4). Even though 

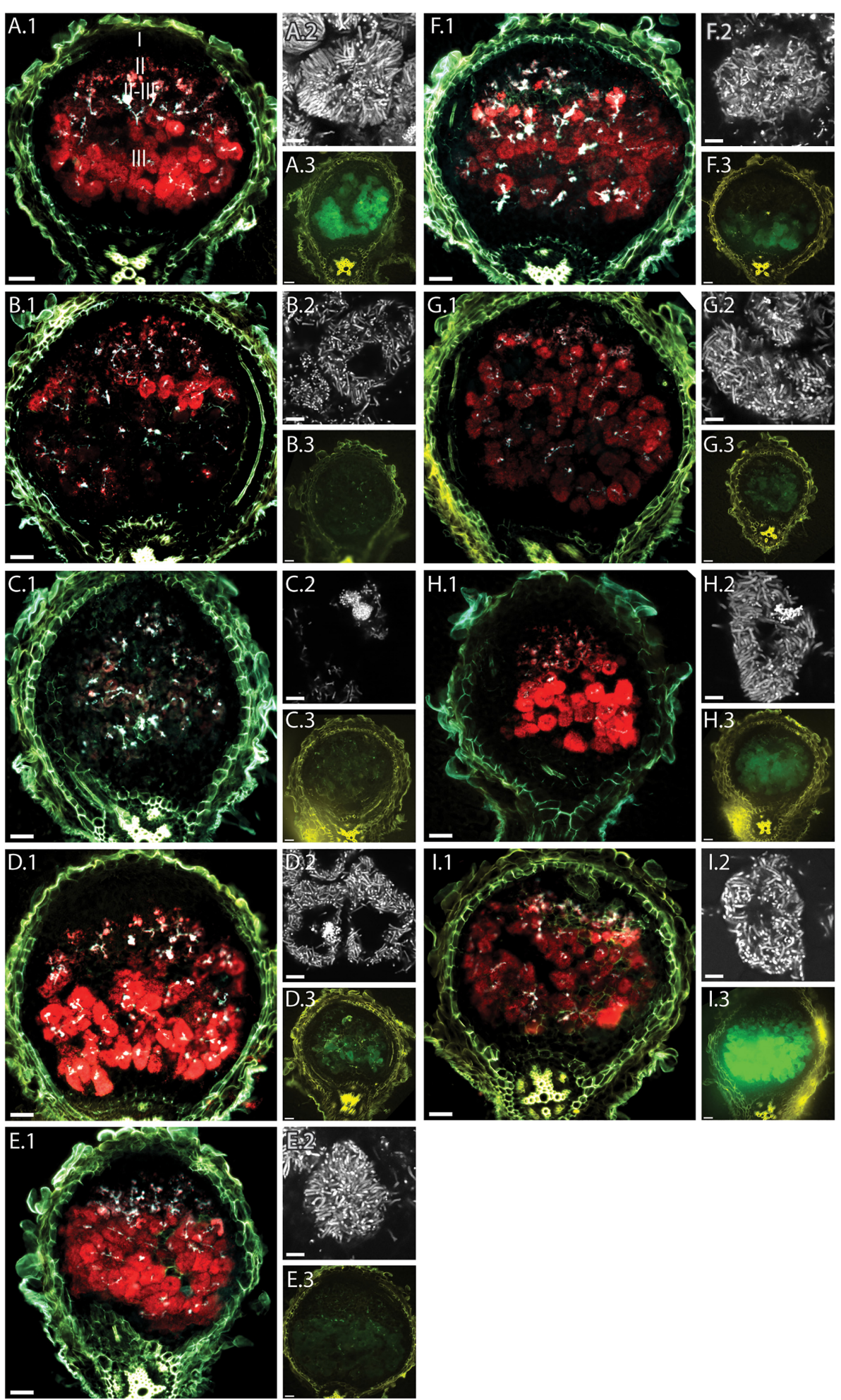

FIGURE 4 | Fluorescence microscopy of root nodules from FNB plant mutants inoculated with CL304. Root nodules from wild type M. truncatula A17 (A) and the mutants 6168 (B), 6265 (C), 6488 (D), 6359 (E), 6469 (F), 6470 (G), 6471 (H), and 6701 (I) were imaged at 17 dpi. The large images (A.1-I.1) are composite wide-field images of the $P_{\text {exo }}$-mTFP (cyan), $P_{\text {bacA }}$ - $m$ Cherry (red), and UV-autofluorescence (yellow) signals. Images (A.2-I.2) are confocal images $P_{\text {bacA }}$ - $m C h e r r y$ labeled bacterial cells within root nodules. Images (A.3-I.3) are composite widefield images of the $P_{\text {nifH }}$-UidA (green) and UV-autofluorescence (yellow) signals in ImaGene Green stained nodules. The different root nodule zones, I (meristem), II (infection), II-III (interzone), and III (nitrogen fixation) are indicated in image (A.1). Scale bars: $50 \mu \mathrm{m}$ (wide field images); $5 \mu \mathrm{m}$ (confocal images). 
imaging ImaGene Green stained cryosections of 17dpi nodules (Figure 4) and counting the number of X-Gluc positive nodules of 28 dpi plants (Figure 5) are very different methods to assess nifH expression similar trends are observed. For instance, $\mathrm{X}$-gluc staining and ImaGene Green staining indicate that nitrogenase expression is severely impaired in 6168 and 6265. For plant line 6488, we observed a strong reduction of $P_{n i f H}$ positive nodules in $28 \mathrm{dpi}$ plants (Figure 5) and low level of $P_{\text {nifH }}$ activity in the cryosections of $17 \mathrm{dpi}$ plants. It is possible that nitrogenase expression is not sustained in 6488, that nitrogenase expression occurs in an insufficient number of nodules, or that nitrogenase expression is too weak. Considering the strong plant phenotype (Figure 3), our results are consistent with the conclusion that nitrogenase expression is severly impaired in 6488 nodules. X-Gluc and ImaGene Green staining experiments are consistent with a slightly impaired nitrogenase expression in 6359, 6469, and possibly 6470 nodules while there appears to be normal nitrogenase expression in 6471 and 6701 nodules. In most plant lines $(6469,6470,6471,6701$, A17), $P_{\text {nifH }}$ activity was observed in the nodule center and the nodule base, where the nitrogen fixation zone is usually found in wild type nodules. In 6359, nodules the $P_{\text {nifH }}$-uidA signal was occasionally seen in the root-proximal third of the nodule but not in the nodule center (Figure 4). This suggests that the expression of nitrogenase subunits may be delayed in 6359 nodules. A much larger sample than the 1015 nodules tested here by the ImaGene Green assay could quantify the reproducibility and the degree of any delay for 6359 nodule maturation. Nodules from FNB mutants displayed similar fluorescence patterns if harvested at 14 (not shown) or $17 \mathrm{dpi}$. The results of all FNB mutant analyses are summarized in Table 1.

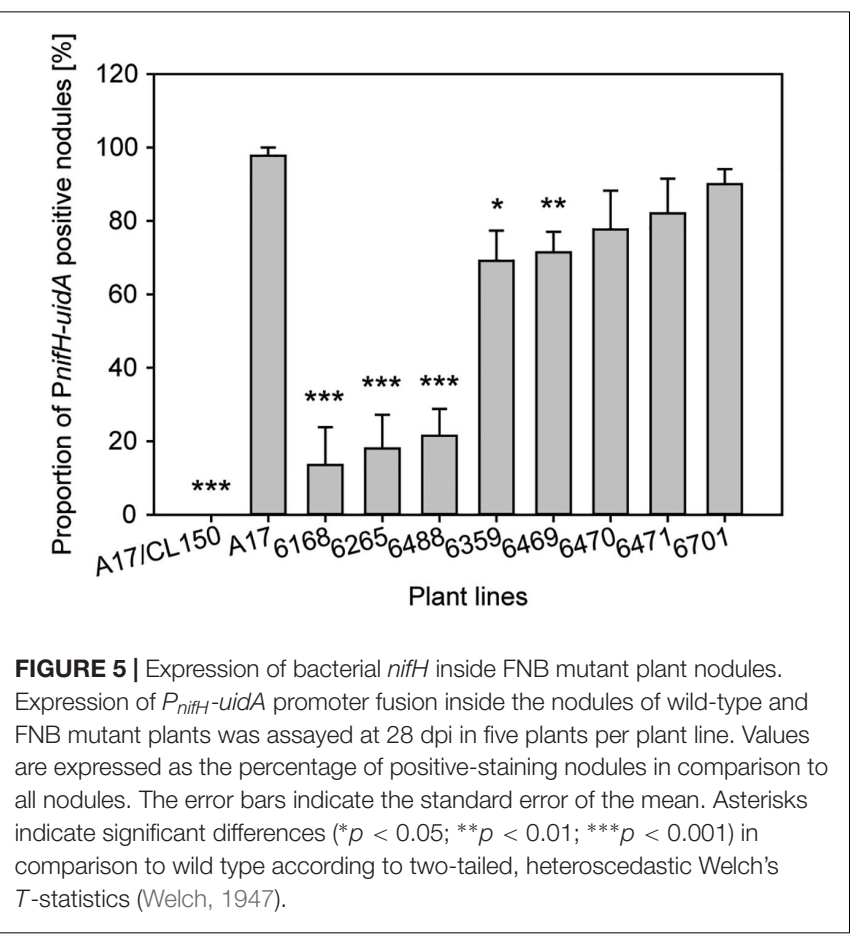

\section{Staining and Microscopy of Purified Nodule Bacteria}

Since the CL304 multireporter was useful to visualize different bacterial populations such as infection thread bacteria and nitrogen fixing bacteroids in the nodule, we were interested if different bacterial populations could also be distinguished by the expression of different marker proteins after extraction from root nodules. To separate bacterial cells from the plant tissue, we crushed frozen nodules and filtered the cell suspension through a Miracloth membrane. Microscopy showed that the filtrate contained bacteria of varying sizes (Figure 6). The teal fluorescence of our nodule bacteria preparation was very weak, and it was not possible to detect $P_{\text {exo }}-m T F P$ signals reliably from single cells. We detected strong $P_{b a c A}$-mcherry signals in small, undifferentiated, rod-shaped bacteria but not in elongated or branched bacteroids. This was unexpected, because we detected $P_{b a c A}$-mcherry expression in individual, elongated bacteroids in cryosections. However, confocal microscopy showed that the signal of individual cells was weaker in differentiated bacteroids than in undifferentiated bacteria (Figure 1P). It is possible that the $P_{b a c A}$-mcherry signal of purified bacteroids was too weak to be detected by conventional wide-field fluorescence microscopy. After staining with ImaGene Green, $P_{n i f H}$-uidA signals were only detected in differentiated, elongated bacteroids. Therefore, the CL304 multireporter strain can be used to distinguish populations of mostly undifferentiated bacteria, that express bacA but not nifH, from elongated, mostly differentiated bacteria, that do express nifH but not $b a c A$, based on cell fluorescence.

\section{DISCUSSION}

The characterization of plant and bacterial symbiosis mutants has been central to elucidating the initial symbiotic plantbacterial signal exchange and to identifying processes that control cell differentiation between both symbiotic partners (Kereszt et al., 2011; Oldroyd, 2013). Large-scale Tnt1, FNB, and EMS mutagenesis screens yielded several hundred $M$. truncatula mutants with defects during later symbiotic stages (The Samuel Roberts Nobel foundation; http://medicago-mutant.noble.org/ mutant/; (Penmetsa and Cook, 2000; Wang et al., 2006; Tadege et al., 2008). So far, few of these mutants have been characterized in detail. Here, we describe the construction of a bacterial multireporter strain for the characterization and initial classification of symbiosis mutants. In addition to a constitutively expressed lac $Z$ fusion this strain contains a

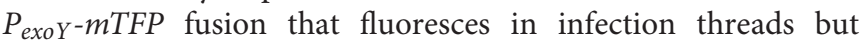
not in differentiated bacteroids, a $P_{b a c A}$-mCherry fusion that fluoresces in infection threads and in differentiated bacteroids and a $P_{n i f H}-u i d A$ fusion which indicates nitrogenase expression. The expression of different reporter genes during different developmental stages makes this strain a useful tool to study root nodule development. Previous uses of fluorescent proteins to label nodule bacteria relied largely on constitutively expressed reporter genes (Stuurman et al., 2000; Pistorio et al., 2002; D'Haeze et al., 2004; Auriac and Timmers, 2007; Pini et al., 2013). We adapted a fluorescent GUS staining protocol and 

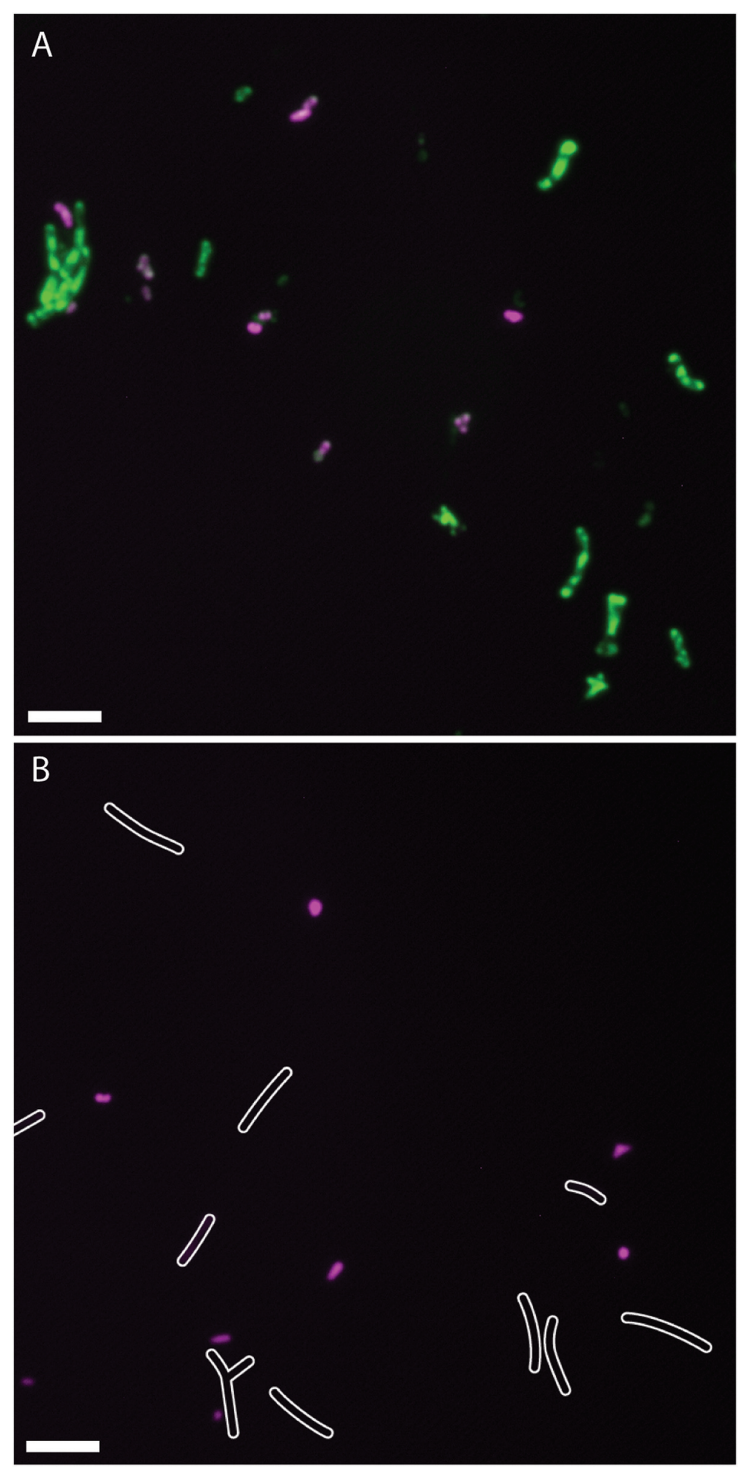

FIGURE 6 | Fluorescence micrographs of Sinorhizobium meliloti CL304 cells purified from root nodules. Bacteria were purified from $17 \mathrm{dpi}$ wild type $M$. truncatula A17 nodules and assayed for the expression of $P_{\text {bacA }}-m$ Cherry (magenta) and $P_{\text {nifH }}$-uidA (green). Bacteria were imaged either after staining for uidA activity with ImaGene Green (A) or without staining (B). White cell outlines were added based on differential interference contrast imaging to indicate the position of weakly fluorescent bacteria in the unstained image. Scale bars: $5 \mu \mathrm{m}$

developed a cryosectioning procedure that is compatible with wide-field and confocal fluorescence microscopy. The fluorescent GUS staining of a $P_{n i f H}-u i d A$ fusion can be used in conjunction with autofluorescent proteins such as mTFP and it provides a highly sensitive alternative to a previously published NifH-GFP fusion (Gavrin et al., 2014). Our procedure makes it possible to observe differences between wild type and mutant nodules in only 2 weeks old nodules. While most fluorescence microscopy studies of root nodules rely on the use of fresh nodule tissue that is processed immediately after nodule harvest (Stuurman et al., 2000; Haynes et al., 2004; Auriac and Timmers, 2007; Domonkos et al., 2013), the use of frozen tissue makes it possible to harvest and analyze root nodules on different days. Using a cryosectioning procedure it is also possible to section multiple nodules simultaneously. Therefore, the cryosectioning procedure makes it possible to cultivate, harvest and section nodules from many plants in parallel, which is essential for medium and high throughput applications.

Analysis of $d n f$ and FNB plant mutants with the $P_{\text {exoY- }} m$ TFP fusion showed that nodules from all tested strains contained exo $Y$-expressing bacteria in infection threads. Since $P_{\text {exoY }}-m T F P$ is expressed specifically in the infection threads, it could be useful to visualize defects in the infection thread network. Our observations here on both the previously known $d n f$ and the new FNB mutants compared to wild type indicate that the mutations in all these plants act downstream of infection thread formation.

When we designed the multireporter strain we expected the $P_{b a c A}$-mCherry fusion specifically to label differentiating bacteroids in interzone II-III. While we observed higher $P_{b a c A^{-}}$ mcherry fluorescence in individual undifferentiated bacterial cells than in differentiated bacteroids by high resolution confocal microscopy, we observed similar fluorescence levels in infection thread bacteria, in differentiating bacteria of interzone IIIII and in fully differentiated bacteroids of zone III using widefield fluorescence microscopy. In widefield microscopy, the intensity difference between differentiated and undifferentiated cells is not as pronounced because the focal plane is broader and signal from multiple layers of bacteroids is detected. The $P_{b a c A}-m$ Cherry fluorescence pattern revealed several differences between the mutants. In one plant line (6168) we detected very little $P_{b a c A}$-mCherry fluorescence indicating that bacteroids do not start to differentiate and/or senesce immediately after release from infection threads in this mutant. Other mutants such as $d n f 5$ and $d n f 6$ displayed unusual $P_{b a c A}-m$ Cherry localization patterns in invaded plant cells. Confinement of the $P_{b a c A^{-}}$ $m$ Cherry signal to the cell periphery suggests that the vacuoles in these mutants are increased in comparison to wild type. The strong $P_{b a c A}-m$ Cherry fluorescence signal enabled us to study the morphology of bacteria within infection threads and invaded plant cells by confocal microscopy and to distinguish mutants with apparently undifferentiated, partially elongated and fully elongated bacteroids. Overall the $P_{b a c A}-m C h e r r y$ fusion has proven useful to detect defects in bacterial release from infection threads, bacteroid differentiation and bacteroid survival.

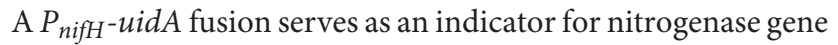
expression. We observed a wide range of $P_{n i f H}-u i d A$ activities in the different mutants, from severely impaired $P_{\text {nifH- }}$ uidA activity in mutants with bacteroid differentiation or survival defects ( $d n f 5, d n f 2,6168$, and 6265 mutants) to intermediate activities ( $d n f 7,6488,6359,6469,6470$, and 6471) and wild type activities in lines $d n f 3$ and 6701 . Our results for $n i f H$ expression in the $d n f 7$ mutant differed slightly from the patterns seen by Horvath et al., as we observed nifH expression in the interzone and distal parts of the nitrogen fixation zone whereas Horvath et al. only observed nifH expression in cells in the interzone (Horváth et al., 2015). The differences may reflect changes of the $P_{n i f H}$-uidA localization pattern with nodule age, since we used 14 and 17 dpi nodules 
whereas Horvath et al used 21 dpi nodules. Since nifH expression is controlled by the FixL/FixJ/NifA regulatory cascade that is mainly activated by microaerobic growth conditions (Soupène et al., 1995; Bobik et al., 2006), low and intermediate $P_{n i f H^{-}}$ uidA activity might arise from defects in the establishment of microaerobic conditions in the nodule. For certain late symbiotic mutants, such as $d n f 3$ and 6701 we cannot detect any differences in $P_{\text {nifH }}$-uidA activity in comparison to wild type. In these cases, processes downstream of nitrogenase expression such as nitrogenase assembly, nitrogenase stability or nutrient exchange between host and microbe may be defective.

Based on microscopic analysis with multi-reporter strain CL304, it is possible to classify nodulation mutants according to different symbiotic stages. The mutants with the earliest and most severe defects are 6265 and $d n f 5$. Bacteria do not differentiate into elongated bacteroids at all in $d n f 5$ nodules; in 6265 , only a few cells are found outside of infection threads, and these bacteria seem to senesce before bacteroid differentiation is completed. Based on these phenotypes, we place the 6265 mutations after the previously characterized IPD3, lin and nip mutants, which have defects in infection thread formation (Kuppusamy et al., 2004; Veereshlingam et al., 2004; Domonkos et al., 2013). The phenotype of the $d n f 5$ mutant is similar to that of the previously described dnf1 mutant (Wang et al., 2010), which is defective in NCR peptide maturation and secretion. In $d n f 1$ and $d n f 5$ nodules, bacteria are released from infection threads into plant cells but do not show signs of differentiation. Behavior of the CL304 multireporter strain in $d n f 1$ nodules was indistinguishable from that in $d n f 5$ nodules (data not shown). This is in agreement with previous studies that found strong similarities between the $d n f 5$ and the $d n f 1$ gene expression profiles (Lang and Long, 2015). In three mutants $(6168, d n f 2, d n f 6)$ bacteroids were only partially elongated. In 6168 mutant nodules, bacteria are released from infection threads and undergo differentiation but seem to senesce rapidly. Similar phenotypes with greatly reduced bacterial abundance in the nitrogen fixation zone were observed in $d n f 8$, $5 \mathrm{~L} / 11 \mathrm{~S}$, and $13 \mathrm{U}$ mutants (Domonkos et al., 2013). In contrast to 6168 , we found partially elongated bacteroids in all zones of $d n f 2$ nodules at $14 \mathrm{dpi}$ which suggests that bacteroid senescence is not as rapid in $d n f 2$ nodules as in 6168 nodules. Premature nodule senescence has also been reported for $d n f 2$ nodules (Bourcy et al., 2012). In $d n f 6$ nodules bacteroids were also not fully elongated. However, in contrast to $d n f 2$ and 6168 nodules, we detected $P_{n i f H}-u i d A$ activity in $d n f 6$ nodules. This suggests that the $d n f 6$ mutation is not as severe as the $d n f 2$ mutation and while the $d n f 6$ mutation seems to affect bacteroid morphology it may not completely block root nodule development.

Mutants $d n f 3, d n f 7,6488,6359,6469,6470,6471$, and 6701 supported the differentiation of fully elongated bacteroids. In comparison to wild type, $P_{\text {nifH }}$-uidA activity was reduced in 6488, 6359,6469 , and 6470 mutants but not in $d n f 7, d n f 3$, and 6701 nodules. With the exception of $d n f 7$ for which we detected wild type like $P_{n i f H}$ expression, our $P_{n i f H}$-uidA expression results in $d n f$ strains are in good agreement with the results from Starker et al., who detected highest $P_{n i f H}-u i d A$ activities in $d n f 3$ and $d n 6$, intermediate activity in $d n f 4$ and $d n f 7$, low activity in $d n f 2$ and no activity in $d n f 1$ and $d n f 5$ nodules (Starker et al., 2006).
When placing the mutants in a developmental context, we note that the FNB mutants have not been backcrossed yet. Therefore, it is possible that a plant line carries several mutations that affect root nodule development. Since there is biological variability even between different root nodules formed by the same plant it is important to study several nodules of the same plant line. In this study, we selected the biggest nodules from 10 to 15 plants per plant line. Using our cryosectioning procedure it was possible to separate nodule harvest and analysis, and to section and stain 10-15 nodules simultaneously. However, since we deliberately selected the most developed nodules of each plant we would not be able to detect a difference to wild type if the phenotype of a mutant was leaky and only a fraction of the nodules were affected. The multireporter strain provides a tool to rapidly characterize plant mutants and should help to identify mutants that warrant further detailed biochemical and genetic characterization.

We have shown in this study that a bacterial multireporter strain with $P_{\text {exoY }}-m T F P, P_{b a c A}-m$ Cherry, and a $P_{n i f H}-u i d A$ fusion can be used to characterize $M$. truncatula root nodule mutants. We chose the $P_{\text {exo }}, P_{\text {bac }}$, and $P_{\text {nifH }}$ promoters because these genes have important functions during different symbiotic stages. In future, other promoters could be selected based on recent transcriptomic data (Roux et al., 2014; Lang and Long, 2015) to target other bacterial nodule subpopulations. In addition to analyzing plant mutants, it was possible to detect reporter gene expression in bacteria that were isolated from root nodules. Therefore, the reporter strain could be used to quantify different bacterial nodule populations. The strain may also facilitate fluorescence activated cell sorting to collect specific bacterial populations for transcriptomic, proteomic or biochemical experiments.

\section{AUTHOR CONTRIBUTIONS}

LS and CL cultivated plant lines and harvested nodules. LS, CL, and $\mathrm{CH}$ constructed bacterial reporter strains. CL carried out cryosectioning, nodule staining, and microscopy. SL, CL, and CH conceived the study and designed experiments. SL and CL wrote the manuscript.

\section{ACKNOWLEDGMENTS}

This work was supported by National Institutes of Health grant no. GM093628 and NSF grant no. 1140396 to SL and a German Academic Exchange Services Postdoctoral Scholarship to CL.

\section{SUPPLEMENTARY MATERIAL}

The Supplementary Material for this article can be found online at: https://www.frontiersin.org/articles/10.3389/fpls.2018.00076/ full\#supplementary-material

FIGURE S1 | Fluorescence microscopy of Sinorhizobium meliloti control strains. The first row (A-E) shows nodules from plants inoculated with the reporter-less, wild type strain CL150. The second row (F-J) shows nodules inoculated with 
strain CL227, which contains the $P_{\text {nifH }}$-UidA fusion but not the pCL301 plasmid with $P_{\text {exoy }}-$ mTFP and $P_{\text {bacA }}-m$ Cherry. The third row $(\mathbf{K}-\mathbf{0})$ shows nodules inoculated with CL296, which contains the pCL301 plasmid but not the $P_{\text {nifH }}$-uidA fusion. The fourth row (P-T) shows nodules from the final reporter strain CL304. The first column (A,F,K,P) shows the mTFP signal, the second column (B, G, L,Q) shows the $m$ Cherry signal, the third column $(\mathbf{C}, \mathbf{H}, \mathbf{M}, \mathbf{R})$ the UV signal, the fourth column (D,I,N,S) an overlay of the mTFP, mCherry, and UV signal, and the fifth column $(\mathbf{E}, \mathbf{J}, \mathbf{O}, \mathbf{T})$ shows an overlay of the uidA and UV signals. All

\section{REFERENCES}

Ai, H.-W., Henderson, J. N., Remington, S. J., and Campbell, R. E. (2006). Directed evolution of a monomeric, bright and photostable version of Clavularia cyan fluorescent protein: structural characterization and applications in fluorescence imaging. Biochem. J. 400, 531-540. doi: 10.1042/BJ200 60874

Alunni, B., and Gourion, B. (2016). Terminal bacteroid differentiation in the legume- rhizobium symbiosis: nodule-specific cysteine-rich peptides and beyond. New Phytol. 211, 411-417. doi: 10.1111/nph.14025

Aslam, S. N., Newman, M. A., Erbs, G., Morrissey, K. L., Chinchilla, D., Boller, T., et al. (2008). Bacterial polysaccharides suppress induced innate immunity by calcium chelation. Curr. Biol. 18, 1078-1083. doi: 10.1016/j.cub.2008. 06.061

Auriac, M. C., and Timmers, A. C. J. (2007). Nodulation studies in the model legume Medicago truncatula: advantages of using the constitutive EF1 alpha promoter and limitations in detecting fluorescent reporter proteins in nodule tissues. Mol. Plant Microbe Interact. 20, 1040-1047. doi: 10.1094/MPMI-20-91040

Barnett, M. J., Toman, C. J., Fisher, R. F., and Long, S. R. (2004). A dual-genome symbiosis chip for coordinate study of signal exchange and development in a prokaryote-host interaction. Proc. Natl. Acad. Sci. U.S.A. 101, 16636-16641. doi: 10.1073/pnas.0407269101

Bobik, C., Meilhoc, E., and Batut, J. (2006). FixJ: a major regulator of the oxygen limitation response and late symbiotic functions of Sinorhizobium meliloti. J. Bacteriol. 188, 4890-4902. doi: 10.1128/JB.00251-06

Bourcy, M., Brocard, L., Pislariu, C. I., Cosson, V., Mergaert, P., Tadege, M., et al. (2012). Medicago truncatula DNF2 is a PI-PLC-XD-containing protein required for bacteroid persistence and prevention of nodule early senescence and defense-like reactions. New Phytol. 197, 1250-1261. doi: 10.1111/nph. 12091

Cheng, H. P., and Walker, G. C. (1998). Succinoglycan is required for initiation and elongation of infection threads during nodulation of alfalfa by Rhizobium meliloti. J. Bacteriol. 180, 5183-5191.

D'Haeze, W., Gao, M. S., and Holsters, M. (2004). A gfp reporter plasmid to visualize Azorhizobium caulinodans during nodulation of Sesbania rostrata. Plasmid 51, 185-191. doi: 10.1016/j.plasmid.2004.01.004

Ditta, G., Schmidhauser, T., Yakobson, E., Lu, P., Liang, X. W., Finlay, D. R., et al. (1985). Plasmids related to the broad host range vector, pRK290, useful for gene cloning and for monitoring gene expression. Plasmid 13, 149-153. doi: 10.1016/0147-619X(85)90068-X

Domonkos, A., Horvath, B., Marsh, J. F., Halasz, G., Ayaydin, F., Oldroyd, G. E. D., et al. (2013). The identification of novel loci required for appropriate nodule development in Medicago truncatula. BMC Plant Biol. 13:157. doi: 10.1186/ 1471-2229-13-157

Dudley, M. E., Jacobs, T. W., and Long, S. R. (1987). Microscopic studies of cell divisions induced in alfalfa roots by Rhizobium meliloti. Planta 171, 289-301. doi: 10.1007/BF00398674

Ehrhardt, D. W., Atkinson, E. M., and Long, S. R. (1992). Depolarization of alfalfa root hair membrane potential by Rhizobium meliloti Nod factors. Science 256, 998-1000. doi: 10.1126/science.10744524

Farkas, A., Maróti, G., Dürgő, H., Györgypál, Z., Lima, R. M., Medzihradszky, K. F., et al. (2014). Medicago truncatula symbiotic peptide NCR247 contributes to bacteroid differentiation through multiple mechanisms. Proc. Natl. Acad. Sci. U.S.A. 111, 5183-5188. doi: 10.1073/pnas.1404169111

Felfoldi, F., Kupihar, Z., Bottka, S., and Puskas, L. G. (1997). Direct ligation of human $\mathrm{CD} 4$ polymerase chain reaction fragment into vectors at specific nodules were harvested at 14 dpi nodules from $M$. truncatula A17. Scale bar: $50 \mu \mathrm{m}$.

\section{TABLE S1 | Plasmids used in this study.}

TABLE S2 | Primers used in this study. fw - forward primer; rev - reverse primer; $P$ - 5'-phosphorylated primer.

TABLE S3 | S. meliloti strains used in this study.

restriction sites with positional heterostagger cloning. Anal. Biochem. 253, 275-277. doi: 10.1006/abio.1997.2402

Fischer, H. M. (1994). Genetic-regulation of nitrogen-fixation in Rhizobia. Microbiol. Rev. 58, 352-386.

Gage, D. J. (2002). Analysis of infection thread development using Gfpand DsRed-expressing Sinorhizobium meliloti. J. Bacteriol. 184, 7042-7046. doi: 10.1128/JB.184.24.7042-7046.2002

Gage, D. J. (2004). Infection and invasion of roots by symbiotic, nitrogen-fixing rhizobia during nodulation of temperate legumes. Microbiol. Mol. Biol. Rev. 68, 280-300. doi: 10.1128/MMBR.68.2.280-300.2004

Gage, D. J., Bobo, T., and Long, S. R. (1996). Use of green fluorescent protein to visualize the early events of symbiosis between Rhizobium meliloti and alfalfa (Medicago sativa). J. Bacteriol. 178, 7159-7166. doi: 10.1128/jb.178.24.71597166.1996

Gavrin, A., Kaiser, B. N., Geiger, D., Tyerman, S. D., Wen, Z., Bisseling, T., et al. (2014). Adjustment of host cells for accommodation of symbiotic bacteria: vacuole defunctionalization, HOPS suppression, and TIP1g retargeting in Medicago. Plant Cell 26, 3809-3822. doi: 10.1105/tpc.114.128736

Gibson, K. E., Kobayashi, H., and Walker, G. C. (2008). Molecular determinants of a symbiotic chronic infection. Annu. Rev. Genet. 42, 413-441. doi: 10.1146/ annurev.genet.42.110807.091427

Glazebrook, J., Ichige, A., and Walker, G. C. (1993). A Rhizobium meliloti homolog of the Escherichia coli peptide antibiotic transport protein SbmA is essential for bacteroid development. Genes Dev. 7, 1485-1497. doi: 10.1101/gad.7. 8.1485

Glazebrook, J., and Walker, G. C. (1989). A novel exopolysaccharide can function in place of the Calcofluor-binding exopolysaccharide in nodulation of alfalfa by Rhizobium meliloti. Cell 56, 661-672. doi: 10.1016/0092-8674(89)90588-6

Gonzalez, J. E., York, G. M., and Walker, G. C. (1996). Rhizobium meliloti exopolysaccharides: synthesis and symbiotic function. Gene 179, 141-146. doi: 10.1016/S0378-1119(96)00322-8

Haag, A. F., Arnold, M. F., Myka, K. K., Kerscher, B., Dall'angelo, S., Zanda, M., et al. (2013). Molecular insights into bacteroid development during Rhizobiumlegume symbiosis. FEMS Microbiol. Rev. 37, 364-383. doi: 10.1111/1574-6976. 12003

Haag, A. F., Baloban, M., Sani, M., Kerscher, B., Pierre, O., Farkas, A., et al. (2011). Protection of Sinorhizobium against host cysteine-rich antimicrobial peptides is critical for symbiosis. PLOS Biol. 9:e1001169. doi: 10.1371/journal.pbio.100 1169

Haney, C. H., and Long, S. R. (2010). Plant flotillins are required for infection by nitrogen-fixing bacteria. Proc. Natl. Acad. Sci. U.S.A. 107, 478-483. doi: $10.1073 /$ pnas.0910081107

Haynes, J. G., Czymmek, K. J., Carlson, C. A., Veereshlingam, H., Dickstein, R., and Sherrier, D. J. (2004). Rapid analysis of legume root nodule development using confocal microscopy. New Phytol. 163, 661-668. doi: 10.1111/j.1469-8137.2004. 01138.x

Horton, R. M., Hunt, H. D., Ho, S. N., Pullen, J. K., and Pease, L. R. (1989). Engineering hybrid genes without the use of restriction enzymes - gene-splicing by overlap extension. Gene 77, 61-68. doi: 10.1016/0378-1119(89)90359-4

Horváth, B., Domonkos, Á., Kereszt, A., Szücs, A., Ábraham, E., Ayaydin, F., et al. (2015). Loss of the nodule-specific cysteine rich peptide, NCR169, abolishes symbiotic nitrogen fixation in the Medicago truncatula dnf7 mutant. Proc. Natl. Acad. Sci. U.S.A. 112, 15232-15237. doi: 10.1073/pnas.1500777112

Karunakaran, R., Haag, A. F., East, A. K., Ramachandran, V. K., Prell, J., James, E. K., et al. (2010). BacA is essential for bacteroid development in nodules of galegoid, but not phaseoloid, legumes. J. Bacteriol. 192, 2920-2928. doi: 10.1128/JB.00020-10 
Kawaharada, Y., Kelly, S., Nielsen, M. W., Hjuler, C. T., Gysel, K., Muszynski, A., et al. (2015). Receptor-mediated exopolysaccharide perception controls bacterial infection. Nature 523, 308-312. doi: 10.1038/nature14611

Kereszt, A., Mergaert, P., and Kondorosi, E. (2011). Bacteroid development in legume nodules: evolution of mutual benefit or of sacrificial victims? Mol. Plant Microbe Interact. 24, 1300-1309. doi: 10.1094/MPMI-06-11-0152

Kevei, Z., Vinardell, J. M., Kiss, G. B., Kondorosi, A., and Kondorosi, E. (2002). Glycine-rich proteins encoded by a nodule-specific gene family are implicated in different stages of symbiotic nodule development in Medicago spp. Mol. Plant Microbe Interact. 15, 922-931. doi: 10.1094/MPMI.2002.15. 9.922

Kim, M., Chen, Y., Xi, J., Waters, C., Chen, R., and Wang, D. (2015). An antimicrobial peptide essential for bacterial survival in the nitrogen-fixing symbiosis. Proc. Natl. Acad. Sci. U.S.A. 112, 15238-15243. doi: 10.1073/pnas. 1500123112

Kondorosi, E., Mergaert, P., and Kereszt, A. (2013). A paradigm for endosymbiotic life: cell differentiation of Rhizobium bacteria provoked by host plant factors. Annu. Rev. Microbiol. 67, 611-628. doi: 10.1146/annurev-micro-092412155630

Kovach, M. E., Elzer, P. H., Hill, D. S., Robertson, G. T., Farris, M. A., Roop, R. M., et al. (1995). Four new derivatives of the broad-host-range cloning vector pBBR1MCS, carrying different antibiotic-resistance cassettes. Gene 166, 175-176. doi: 10.1016/0378-1119(95)00584-1

Kuppusamy, K. T., Endre, G., Prabhu, R., Penmetsa, R. V., Veereshlingam, H., Cook, D. R., et al. (2004). LIN, a Medicago truncatula gene required for nodule differentiation and persistence of rhizobial infections. Plant Physiol. 136, 3682-3691. doi: 10.1104/pp.104.045575

Lang, C., and Long, S. R. (2015). Transcriptomic analysis of Sinorhizobium meliloti and Medicago truncatula symbiosis using nitrogen fixation-deficient nodules. Mol. Plant Microbe Interact. 28, 856-868. doi: 10.1094/MPMI-12-140407-R

Lehman, A. P., and Long, S. R. (2013). Exopolysaccharides from Sinorhizobium meliloti can protect against $\mathrm{H}_{2} \mathrm{O}_{2}$-dependent damage. J. Bacteriol. 195, 5362-5369. doi: 10.1128/JB.00681-13

Leong, S. A., Williams, P. H., and Ditta, G. S. (1985). Analysis of the 5' regulatory region of the gene for delta-aminolevulinic acid synthetase of Rhizobium meliloti. Nucleic Acids Res. 13, 5965-5976. doi: 10.1093/nar/13.16.5965

Lodwig, E., and Poole, P. (2003). Metabolism of Rhizobium bacteroids. Crit. Rev. Plant Sci. 22, 37-78. doi: 10.1080/713610850

Long, S., Mccune, S., and Walker, G. C. (1988). Symbiotic loci of Rhizobium meliloti identified by random TnphoA mutagenesis. J. Bacteriol. 170, 4257-4265. doi: 10.1128/jb.170.9.4257-4265.1988

Long, S. R. (2015). Symbiosis: receptive to infection. Nature 523, 298-299. doi: 10.1038 /nature 14632

Meade, H. M., Long, S. R., Ruvkun, G. B., Brown, S. E., and Ausubel, F. M. (1982). Physical and genetic characterization of symbiotic and auxotrophic mutants of Rhizobium meliloti induced by transposon Tn5 mutagenesis. J. Bacteriol. 149, $114-122$.

Müller, P., Keller, M., Weng, W. M., Quandt, J., Arnold, W., and Pühler, A. (1993). Genetic analysis of the Rhizobium meliloti exoYFQ operon: ExoY is homologous to sugar transferases and ExoQ represents a transmembrane protein. Mol. Plant Microbe Interact. 6, 55-65. doi: 10.1094/MPMI-6-055

Oke, V., and Long, S. R. (1999). Bacterial genes induced within the nodule during the Rhizobium-legume symbiosis. Mol. Microbiol. 32, 837-849. doi: 10.1046/j. 1365-2958.1999.01402.x

Oldroyd, G. E. D. (2013). Speak, friend, and enter: signalling systems that promote beneficial symbiotic associations in plants. Nat. Rev. Microbiol. 11, 252-263. doi: 10.1038/nrmicro2990

Ott, T., Van Dongen, J. T., Günther, C., Krusell, L., Desbrosses, G., Vigeolas, H., et al. (2005). Symbiotic leghemoglobins are crucial for nitrogen fixation in legume root nodules but not for general plant growth and development. Curr. Biol. 15, 531-535. doi: 10.1016/j.cub.2005.01.042

Pan, H., and Wang, D. (2017). Nodule cysteine-rich peptides maintain a working balance during nitrogen-fixing symbiosis. Nat. Plants 3:17048. doi: 10.1038/ nplants.2017.48

Pellock, B. J., Cheng, H. P., and Walker, G. C. (2000). Alfalfa root nodule invasion efficiency is dependent on Sinorhizobium meliloti polysaccharides. J. Bacteriol. 182, 4310-4318. doi: 10.1128/JB.182.15.4310-4318.2000
Penmetsa, R. V., and Cook, D. R. (2000). Production and characterization of diverse developmental mutants of Medicago truncatula. Plant Physiol. 123, 1387-1397. doi: 10.1104/pp.123.4.1387

Pinedo, C. A., and Gage, D. J. (2009). Plasmids that insert into the rhamnose utilization locus, rha: a versatile tool for genetic studies in Sinorhizobium meliloti. J. Mol. Microbiol. Biotechnol. 17, 201-210. doi: 10.1159/0002 42446

Pini, F., Frage, B., Ferri, L., De Nisco, N. J., Mohapatra, S. S., Taddei, L., et al. (2013). The DivJ, CbrA and PleC system controls DivK phosphorylation and symbiosis in Sinorhizobium meliloti. Mol. Microbiol. 90, 54-71. doi: 10.1111/mmi. 12347

Pislariu, C. I., Murray, J. D., Wen, J., Cosson, V., Muni, R. R. D., Wang, M., et al. (2012). A Medicago truncatula tobacco retrotransposon insertion mutant collection with defects in nodule development and symbiotic nitrogen fixation. Plant Physiol. 159, 1686-1699. doi: 10.1104/pp.112. 197061

Pistorio, M., Balague, L. J., Del Papa, M. F., Pich-Otero, A., Lodeiro, A., Hozbor, D. F., et al. (2002). Construction of a Sinorhizobium meliloti strain carrying a stable and non-transmissible chromosomal single copy of the green fluorescent protein GFP-P64L/S65T. FEMS Microbiol. Lett. 214, 165-170. doi: 10.1111/j. 1574-6968.2002.tb11341.x

Prell, J., and Poole, P. (2006). Metabolic changes of rhizobia in legume nodules. Trends Microbiol. 14, 161-168. doi: 10.1016/j.tim.2006.02.005

Ribeiro, C. W., Baldacci-Cresp, F., Pierre, O., Larousse, M., Benyamina, S., Lambert, A., et al. (2017). Regulation of differentiation of nitrogen-fixing bacteria by microsymbiont targeting of plant thioredoxin s1. Curr. Biol. 27, 250-256. doi: 10.1016/j.cub.2016.11.013

Roux, B., Rodde, N., Jardinaud, M.-F., Timmers, T., Sauviac, L., Cottret, L., et al. (2014). An integrated analysis of plant and bacterial gene expression in symbiotic root nodules using laser-capture microdissection coupled to RNA sequencing. Plant J. 77, 817-837. doi: 10.1111/tpj.12442

Schlüter, J. P., Reinkensmeier, J., Barnett, M. J., Lang, C., Krol, E., Giegerich, R., et al. (2013). Global mapping of transcription start sites and promoter motifs in the symbiotic alpha-proteobacterium Sinorhizobium meliloti 1021. BMC Genomics 14:156. doi: 10.1186/1471-2164-14-156

Soupène, E. M., Foussard, P., Boistard, G., Truchet, G., and Batut, J. (1995). Oxygen as a key developmental regulator of Rhizobium meliloti $\mathrm{N}_{2}$-fixation gene expression within the alfalfa root nodule. Proc. Natl. Acad. Sci. U.S.A. 92, 3759-3763. doi: 10.1073/pnas.92.9.3759

Starker, C. G., Parra-Colmenares, A. L., Smith, L., Mitra, R. M., and Long, S. R. (2006). Nitrogen fixation mutants of Medicago truncatula fail to support plant and bacterial symbiotic gene expression. Plant Physiol. 140, 671-680. doi: $10.1104 /$ pp. 105.072132

Stuurman, N., Bras, C. P., Schlaman, H. R. M., Wijfjes, A. H. M., Bloemberg, G., and Spaink, H. P. (2000). Use of green fluorescent protein color variants expressed on stable broad-host-range vectors to visualize rhizobia interacting with plants. Mol. Plant Microbe Interact. 13, 1163-1169. doi: 10.1094/MPMI.2000.13.11. 1163

Swanson, J. A., Mulligan, J. T., and Long, S. R. (1993). Regulation of syrM and nodD3 in Rhizobium meliloti. Genetics 134, 435-444.

Tadege, M., Wen, J. Q., He, J., Tu, H. D., Kwak, Y., Eschstruth, A., et al. (2008). Large-scale insertional mutagenesis using the Tnt1 retrotransposon in the model legume Medicago truncatula. Plant J. 54, 335-347. doi: 10.1111/j.1365313X.2008.03418.X

Tiricz, H., Szücs, A., Farkas, A., Pap, B., Lima, R. M., Maróti, G., et al. (2013). Antimicrobial nodule-specific cysteine-rich peptides induce membrane depolarization associated changes in the transcriptome of Sinorhizobium meliloti. Appl. Environ. Microbiol. 79, 6737-6746. doi: 10.1128/AEM. 01791-13

Truchet, G. L., and Dazzo, F. B. (1982). Morphogenesis of lucerne root nodules incited by Rhizobium meliloti in the presence of combined nitrogen. Planta 154, 352-360. doi: 10.1007/BF00393915

Udvardi, M., and Poole, P. S. (2013). Transport and metabolism in legume-rhizobia symbioses. Annu. Rev. Plant Biol. 64, 781-805. doi: 10.1146/annurev-arplant050312-120235

Van de Velde, W., Zehirov, G., Szatmari, A., Debreczeny, M., Ishihara, H., Kevei, Z., et al. (2010). Plant peptides govern terminal differentiation of bacteria in symbiosis. Science 327, 1122-1126. doi: 10.1126/science.1184057 
Vasse, J., De Billy, F., Camut, S., and Truchet, G. (1990). Correlation between ultrastructural differentiation of bacteroids and nitrogen fixation in alfalfa nodules. J. Bacteriol. 172, 4295-4306. doi: 10.1128/jb.172.8.4295-4306. 1990

Veerappan, V., Jani, M., Kadel, K., Troiani, T., Gale, R., Mayes, T., et al. (2016). Rapid identification of causative insertions underlying Medicago truncatula Tnt1 mutants defective in symbiotic nitrogen fixation from a forward genetic screen by whole genome sequencing. BMC Genomics 17:141. doi: 10.1186/ s12864-016-2452-5

Veereshlingam, H., Haynes, J. G., Penmetsa, R. V., Cook, D. R., Sherrier, D. J., and Dickstein, R. (2004). nip, a symbiotic Medicago truncatula mutant that forms root nodules with aberrant infection threads and plant defense-like response. Plant Physiol. 136, 3692-3702. doi: 10.1104/pp.104.049064

Wang, D., Griffitts, J., Starker, C., Fedorova, E., Limpens, E., Ivanov, S., et al. (2010). A nodule-specific protein secretory pathway required for nitrogen-fixing symbiosis. Science 327, 1126-1129. doi: 10.1126/science.11 84096

Wang, H. L., Li, G. M., and Chen, R. J. (2006). "Fast neutron bombardment (FNB) mutagenesis for forward and reverse genetic studies in plants," in Floriculture,
Ornamental and Plant Biotechnology: Advances and Topical Issues, ed. J. A. Teixeira da Silva (Isleworth: Global Science Books).

Welch, B. L. (1947). The generalisation of student's problems when several different population variances are involved. Biometrika 34, 28-35.

Xiao, T. T., Schilderink, S., Moling, S., Deinum, E. E., Kondorosi, E., Franssen, H., et al. (2014). Fate map of Medicago truncatula root nodules. Development 141, 3517-3528. doi: 10.1242/dev.110775

Conflict of Interest Statement: The authors declare that the research was conducted in the absence of any commercial or financial relationships that could be construed as a potential conflict of interest.

Copyright (c) 2018 Lang, Smith, Haney and Long. This is an open-access article distributed under the terms of the Creative Commons Attribution License (CC BY). The use, distribution or reproduction in other forums is permitted, provided the original author(s) and the copyright owner are credited and that the original publication in this journal is cited, in accordance with accepted academic practice. No use, distribution or reproduction is permitted which does not comply with these terms. 